nic heat transport would be required to melt all sea ice, then use that elevated transport as input to their GCM. Because the two studies make assumptions at opposite ends of the spectrum of possibilities for sea-ice feedback, they evidently bracket the truth between them, but the gap is uncomfortably large. Rind and Chandler claim an ice-eradicating oceanic circulation is "not entirely unreasonable" and, although they shy away from estimating the volume transports implied, these bear out their claim: at $60^{\circ} \mathrm{N}$ latitude, oceanic heat flows poleward at the rate of $10^{15}$ watts (twice the estimated present-day value), and sea surface temperature increases to $10{ }^{\circ} \mathrm{C}$, so that if bottom water remains at about $3{ }^{\circ} \mathrm{C}$, the volume transport must be $3.4 \times 10^{7} \mathrm{~m}^{3}$ $\mathrm{s}^{-1}$, not an outrageous increase over Broecker's estimate of $2 \pm 0.5 \times 10^{7} \mathrm{~m}^{3}$ $\mathrm{s}^{-1}$ for present-day North Atlantic Deep Water formation ${ }^{7}$.

Rind and Chandler also note that "climate feedbacks which influence the winddriven surface circulation and the deep water thermohaline circulation would appear to be in the right direction to sustain the increased [oceanic heat] transports". The feedbacks are straightforward. Expansion of subtropical maxima in surface atmospheric pressure leads through geostrophy to enhanced anticyclonic wind vorticity (in oceanographers' terms, negative windstress curl). In other words, the strength increases for both east winds at low latitudes and west winds at high latitudes, which would be expected to increase warm poleward boundary currents such as the Gulf Stream. Simultaneously the disappearance of sea ice leads to greater evaporation in polar seas, which would lead to greater surface salinity and presumably an increased densitydriven overturning circulation involving warm poleward surface currents and cold equatorward deep currents. However, as Rind and Chandler point out, elucidation of "whether the magnitude of the ocean dynamical changes is appropriate will have to await the development of coupled atmosphere/ocean models".

Despite their radically different assumptions about sea ice, our work and that of Rind and Chandler share one important general conclusion: the climate resulting from enhanced oceanic heat transport is quite different from that resulting from the greenhouse effect, with much more warming at the poles and much less warming (even cooling, in our simulation) in the tropics. Although geological evidence such as from the Vostok ice cores shows greenhouse gas concentrations to be correlated with past global temperatures, the changing concentrations could be more an effect of altered ocean circulation than a primary cause of the temperature variations. If Earth's climate history was generated more by variations of oceanic heat transport than by variations of atmospheric composition - a possibility I find difficult to ignore after reading Rind and Chandler's paper - then using direct analogy with past climates to estimate the global warming expected from the human contribution to greenhouse gases is a questionable exercise, and we must depend more than ever on computer models to forecast the climate of the next century. That is a disconcerting prospect given the notorious 'climate drift' of coupled oceanic-atmosphere GCMs (possibly connected to the difficulties with time scale discussed above) ${ }^{8}$.

What are the logical next steps in elucidating ocean/climate interactions? The long timescales of oceanic circulation can be accommodated by accelerated forcing to equilibrium ${ }^{9}$ or by filtering out irrelevant (we hope) 'fast dynamics'10. Thus equipped, oceanic GCMs can at least stand on their own and address the mirror image of the question that Rind and Chandler posed: given an atmospheric climate thought to represent Earth in the past, what is the oceanic circulation? (First results from this sort of exercise are disturbing: Barron and Peterson ${ }^{11}$ find Cretaceous ocean circulation just the opposite of conventional expectations.) Certainly oceanographers interested in climate can formulate their GCMs' boundary conditions more cleverly than is traditionally done - with relaxation to observed surface temperature ${ }^{12}$, which yields the curious property that when model-simulated sea surface temperatures agree precisely with observations, energy flux into or out of the oceans (and hence oceanic heat transport) is precisely zero. And although construction of validated, fully coupled models of the oceans atmosphere, biosphere and cryosphere is a daunting goal, the appropriate tool in the form of raw computing power, may soon be available with the arrival of massively parallel computers. Whatever the difficulty of the questions, the importance of the answers guarantees future attention to the oceans' impact on climate.

Curt Covey is at Lawrence-Livermore National Laboratory, PO Box 808, L-264, Livermore, California 94550, USA.

1. Rind, D. \& Chandler, M. J. geophys. Res. 96, 7437-7461 (1991)

2. Vonder Haar, T. H. \& Oort, A H. J. phys. Oceanogr. 3 , 169-172 (1973)

3. Covey, C. \& Barron. E. Earth Sci. Rev. 24, 429-445 (1988).

4. Broecker, W. S. Nature 238, 123-126 (1987)

5. Bryan, K., Manabe, S. \& Pacanowski, R. C. J. phys. Oceanogr. 5, 30-46 (1975).

6. Covey, C. \& Thompson, S. L. Palaeogeog. Palaeoclim Palaeoecol. 75, 331-341 (1989).

7. Broecker, W. S. Oceanography (submitted)

8. Neelin, J. D. et al. Climate Dynamics (submitted)

9. Bryan, K. J. phys. Oceanogr. 14, 666-673 (1984).

10. Bacastow, R. \& Maier-Reimer, E. Climate Dynamics 4 95-126 (1990)

11. Barron, E. \& Peterson, W. H. Science 244, 684-686 (1989)

12. Haney, R. L. J. phys. Oceanogr. 1. 241-248 (1971).

\section{Automatic marks}

EVERY academic year, students and examiners confront each other in the painful scholastic ritual of examinations. In scientific subjects, the questions at least have a right answer for the examiner to look for. But the marking of essays and appreciations, a crucial element of liberal education, is harder to automate. Daedalus is working on it.

He recalls the way in which psychologists measure personality. They draw up a list of several thousand silly questions, and put them to subjects whose personalities have been evaluated by the most informed and intensive methods. Analysis of the outcome usually shows that a few hundred of the resulting silly answers correlate highly with, and seem good predictors for, certain established aspects of the subjects' personalities. These predictive questions then form a 'multiphasic inventory' which can be applied to further subjects.

So Daedalus is trying this idea out on examination essays. Computer-analysis is already used for testing authorship, and simple indices like the 'fog-index' of writing, a measure of average word-length, are widely recognized. DREADCO educationalists are subjecting a set of traditionally-marked essays to thousands of similar computerized tests. The semicolon to comma ratio, the number of words used exactly twice, the balance between odd and even letters of the alphabet, the fractional occurrence of the word 'involved' - all are being determined. Most of these tests will show no predictive value. But a small proportion will be found to correlate with the assessed worth of the answer. Further answers can be marked purely by computerevaluating these successful measures.

The resulting 'educational multiphasic inventories' will have to be kept secret. They will also need updating. Progressive and alert examining boards will periodically recalibrate their inventories against intensively-marked papers, just as a good factory regularly checks its shop-floor instruments in the standards laboratory. But the routine agony of conscientious marking, the struggle to understand what (if anything) the candidate is trying to say, will be eliminated.

Good riddance, says Daedalus. In his view, examinations don't measure understanding anyway. They measure 'grip': the ability to assess the best practical way of meeting a challenge. If the examinations were held under water, the same people would come top. They would be the ones who would work out the best way to answer an examination under water. They will respond to the new computerized challenge just as well.

DAVID JONES 